\title{
Assessmentof the Effects of Acupuncture in Health and Well- Being of Pets
}

\author{
Heliza Palma Pinheiro Cruz ${ }^{1}$; João Cláudio Costa Ribeiro ${ }^{1}$, Maria Leonora \\ Veras deMello'; Denise de Mello Bobany ${ }^{2}$ \\ ${ }^{1}$ Academic - Veterinary Medicine - UNIFESO - Teresopolis, RJ Brazil \\ ${ }^{2}$ Professors - Veterinary Medicine-Centro Universitario Serra dos Orgãos - UNIFESO - Teresopolis, RJ Brazil
}

\begin{abstract}
Acupuncture has been an effective aid method in human medicine in many circumstances. In animals, it has also been used for millennia by the Chinese, especially in horses and farm animals. More recently, in the West, has been increasingly widespread applicability in companion animals, especially in dogs and cats, as well as wild animals, to alleviate the painful conditions, and restoring health in acute and chronic diseases, for example, articular, neurological, dermatological disorders, respiratory, hemodynamic, and behavioral changes. This research has provided the veterinary students studying the bases of traditional Chinese medicine and its use in acupuncture techniques, as the diagnostic methods used in this practice, the technique of applying the needles, the use of moxibustion and electroacupuncture, so as the development of its accuracy in observation of treatment and its evolution, which will facilitate them in the future entry into a specialization that will complete their training in this area. The College students haveattended sessions at the Clinical School of the College of Veterinary Medicine of UNIFESO, becoming familiarized with the techniques and reinforcing concepts for soon are also doing the treatments. They are also supporting the monitoring and marking of consultations, noting and recording observations on each event attended.
\end{abstract}

Keywords:Acupuncture, welfare, veterinary medicine, traditional chinese medicine

\section{Introduction}

Learning in Veterinary Acupuncture has been adding treatment possibilities in all animal species, as well as in human medicine. Can help as single or complementar treatment in musculoskeletal disorders: post operative orthopedic surgery; osteoarthrosis; the hip dysplasia, elbow; myofascial pain syndromes. In neurological disorders: intervertebral disc disease; stroke; convulsion; peripheral neuropathies; vestibular disorders; sequelae of distemper; degenerative myelopathy. In the gastro-intestinais disorders: nausea, vomiting, diarrhea, or abdominal pain constispação. In dermatological disorders: allergic dermatitis, dermatologic chronic disease, otitis externa, difficult wounds healing. In cardiovascular and respiratory diseases: rhinitis, bronchitis, chronic cough, circulatory disorders, asthma, respiratory allergic conditions. In urogenital disorders: urinary incontinence, urinary tract infections, chronic kidneydisease.This therapy yet it is useful in immune-mediated and behavior disorders [1-4].

\subsection{The four main principles of acupuncture}

Traditional Chinese Medicine, on which Acupuncture is based, aims at balancing the body and the external environment. So, within the theoretical contents studied so far, its main principles are: Theory of Ying / Yan; Theory of the five elements; Energy (Qi) that flows through the meridians; Theory of diagnosis by 8 Principles [5-6].

To understand the treatment of animalsconsulted there was an initial reading of its principles:

1.1.1Theory of Ying / Yan:Yin and Yang are the fundamental concept of traditional Chinese Medicine. They are the basis of diagnosis and treatment. Yin is the feminine, passive, negative principle in nature. Yang - is the beginning of a positive nature, active, male. Yin and Yang are opposites, but follow some laws:

- Interdependence: can not exist without the other.

- Mutual Interconsumption-Yin and Yang are in a constant state of change, so that when one increases the other is consumed. Consumption of Yin leads to a gain of Yang and Yang consumption leads to a gain of Yin.

- Intertransformation-Yin and Yang can transform each other. This transformation occurs when conditions are reaching their limit. For example, the end of the day started the night as well as the actual cycle of the seasons in a case other. The phase boundary of a Yin or Yang cycle will determine the beginning of a new opposite phase[1,3,7].

1.1.2The Five Elements theory:Wood; Fire; Earth; Metal and Water [4]:

- Wood corresponds to the Liver and Gallbladder. Their properties are flexibility and growth; planning; organization; vision; assertiveness; frustration. 
- Fire corresponds to the Heart, Pericardium and Small Intestinewith its action on Sympathetic and Parasympathetic Nervous System.

- Earth corresponds to the Stomach, Spleen and Digestive processes which determine characteristics such asnourichment; contentement; stability; adaptability; empathy and care.

- Metal corresponds to the Lungs, Large Intestine and Skin, responsible for receptivity and purity; inner solutions; ability to continue; self-worth and justice.

- Water corresponds to the Kidneys, Bladder, Bones and Endocrine System, where there arethe deeper reserves of energy;movement and flow; willpower andcourage.

The five elements are produced and controlled among themselves in two constant cycles: the Generation Cycle at where besides producing them mutually, they favor their respective growth - Wood produces Fire, Fire produces the Earth; Earth produces Metal; Metal produces Water and Water produces Wood. There is a successive generation in an uninterrupted cycle. And the Cycle of Control in which the elements govern and restrict themselves - Wood dominates the Earth; Earth dominates the Water; Water dominates the Fire; Fire dominates Metal and Metal dominates wood $[4,10]$

\subsubsection{Energy $(Q i)$ and its derivatives}

$Q \mathrm{i}$ is one of the vital substances that permeate the body. According to its location and function in the body, the $Q i$ will manifest as [1]:

- $G u Q i$ - energy food, the first phase of food processing in Qi.

- Qi Zheng - true power is the union of Ying Qi to Wei Qi.

- Ying $Q i$ - energy nutrition, found predominantly within the body is the main energy circulation in the Primary Channels.

- Wei $Q i$ - defensive Qi, predominantly appears on the outside of the body, with the function to protect and warm the body, and to control the pores, perspiration and hair shine.

- Zhong $Q i$ - energy of the chest, nourishes the Heart (Xin) and the Lung (Fei), promoting breathing and heartbeat.

- Yuan $Q i$ - original energy is the Essence (Jing) in the form of Qi, stimulates and boosts the vital activities of the body.

- $\quad$ Qing $Q i$ - energy of the sky and air.

- Xie Qi-energy perverse (which causes disease).

$Q i$ is the energy that circulates in the meridians is the flame that sustains life and puts the moving beings. $Q i$ is the movement itself, is the life force, is the thread [8,9].Meridian is a channel that runs beneath the surface of the skin and through which the $Q i$ energy. The meridians form a network connecting all parts of the body. They are not physically visible, but its existence and distribution through the body has been amply demonstrated by measurement of potential neuroelectrical. Each acupuncture point has a defined and specific function based on the response of the body [10,11] .In Acupuncture each organ is called Zang and each viscera is called Fu, and each has a specific form of Qi. Meridians or Main Channels are also called Jing Zheng and are as follows: Lung; Large intestine; Stomach; Spleen; Heart; Small intestine; Bladder, kidney; Pericárido; Triple Heater; Gallbladder and Liver $[10,11,12]$.There are still many other channels or meridians accessories, where an cites two very important: Governor Vessel and Conception Vessel $[10,11,12]$.

Another essential ingredient is Jing is the essence, a kind of vital energy in organic physiology that lies in the Kidney (Shen). Jing determines the stages of growth, development, reproduction, and also designs and pregnancy, and consists of two aspects [11].

- Prenatal Jing - is the innate, ancestral essence, that will determine the basic constitution and vitality of the individual. This fraction of Jing can not be replaced throughout life, since it is born with a certain amount of it, from the parents but can be cared for properly through healthy habits feeding, breathing, sex life, among other factors.

- Postnatal Jing - is the essence acquired through food, liquids and also breathing (air), from which the Qi will be produced in the body. It is connected directly to the Spleen (Pi) and stomach (Wei), due to their role in digestion and processing of food and drinks.

Then, it is studied over an essential ingredient, Jin Ye or body fluids that are derived from foods and liquid and formed from many processes of transformation and separation, after which fall into two portions [4]:

- Jin Yang is the fraction, more subtle, the body fluids, circulating on the outside of the body along with the Wei $Q i$, with the function of the nourish and moisten skin, muscles, ligaments and tendons.

- Ye is the Yin fraction, densest, the Jin Ye, circulates inside the body along with Xue and Ying Qi, with the moistening function and nourish Zang $F u$ (organs and viscera), bone marrow, joints. Ye also part of the waste (feces and urine).

There are still two essential substances to study: Xue and Shen. Xue, roughly translated as "blood" in the traditional Chinese medicine has a different connotation of the West, and can not be separated from $Q i$, that 
moves Xue. Blood has the function to nourish and moisten the body, in addition to lead and support the Mind (Shen). Shen is Mind, Spirit or Consciousness. Within the Eastern design, lies in the heart (Xin), is what gives vitality, mental health and strength of personality. Can be realized through the "shining eyes", determines sleep and emotional state of the individual.

\subsubsection{Theory of diagnosis by 8 Principles}

One of diagnosis used in Acupuncture, called the theory of Eight Principles ( $B a$ Gang), which are: interior and exterior; cold and heat; deficiency and excess and Yin and Yang. This system is based on quality, quantity and location of a problem [13]. And by the Eight Principles, other aspects of the external environment are taken into account, as these can also affect the individual. They are known as external pathogenic factors (Six excesses). They can become "pathological" and threatening to the animal, if conditions are severe and the animal is weakened. External pathological factors are: windy weather, humidity, summer heat and dryness $[1,13]$

\subsection{Electroacupunture and Moxabustion}

To assist in palliative and curative needles, there are some other methods. At the Clinical School of the Faculty of Veterinary Medicine of UNIFESO, it has been used electroacupuncture and moxibustion.

\subsubsection{Electroacupunture}

The electroacupuncture is used to enhance the effects of acupuncture done with needles. It has an analgesic action faster, around 10 to 20 minutes. It has the advantage that the needles remain inserted stably coupled to the electrodes and therefore painless to the patient. Used most often smaller number of needles to produce analgesia. Can promote both anesthetic as analgesia, whereas the needles of the mechanical stimulation, promotes just analgesia [7,14].

\subsubsection{Moxibustion}

Moxibustion is a technique where the application of moxa, made through the medicinal herb Artemisia vulgaris, aims to circulate the Qi and warm the Xue of Meridians, increasing energy velocity and enhancing the nutrition and activity of the Zang $F u$, reestablishing the energy balance in cases of deficiency of Yangenergy channels. It also aims to circulate and regulate the body fluids of channels and bring water to nourish and regulate the Yang of Zang Fu[3,15]. The main mechanisms of action of moxibustion are: $Q i$ removal stagnant in the meridians, circulation regulation Xue, toning and revitalizing the Yang, or activating the $Q i$ and Xue circulation, which in Western medical terms can be interpreted as stimulation central nervous system, stimulation of blood circulation, stimulation of cortical function, promoting metabolism or organic immunological stimulation $[3,12,15]$. It is contraindicated for disease treatments with pictures of fever, traumatic skin lesions, mental health problems, young patients or frail elderly, very weakened patients and at the abdomen of pregnant patients, areas near the genitals, nipples and face, on large blood vessels, prominent tendons or large skin folds [15].

\section{Materials and Methods}

Weekly attendance of the animals served in Veterinary Clinical School of the Faculty of Veterinary Medicine of UNIFESO Teresópolis, Rio de Janeiro State, Brazil. The number of sessions is determined by the severity of the problem and the degree of response to treatment. Metallic needles are used the brand "Dongbang" with the following sizes: $0,20 \times 0,15 ; 0,18,0,8 ; 0,20 \mathrm{X} 0,30$. The moxas Artemisia brand "Yang Dong". And yet the electroacupuncture device "Sikuro" model DS100 jr, bivolt.

From June to September 2016 we were treated eleven (11) following related animals:

1)Canine Abraham - SRD, male, 18 years old.

Main complaint: flaccid paraplegia after falling from laje.Rx shows wear discs marked decrease thoracolumbar intervertebral space.

Points used: 23B, Bai Hui, 34VB, 36E, 54B, 3R, 30VB.

2) Canine Cherie - daschound, female, 6 years.

Main complaint: sudden paralysis posteriors acute hernia (spontaneous) in thoracolumbar region.

Points used: B23, and 36, BP6, B40, B60, VG 13, VG 16, VG 20, BP 34, Bai Hui, ashi points.

Results: partial improvement, requiring seminal application. Used needles, electro-acupuncture and moxibustion.

3) Canine Doll. Rottweiller, female, 7 years.

Main complaint: MPD claudication due to pain caused by patellar arthrosis.

Used Points: BP6, F2, local points (knee eyes) VB34, VB40, B40, Bai Hui.

Results: overall improvement, with monthly maintenance applications. Used needles and moxibustion.

4) Feline Boneca- S.R.D. female, approximate age 2 years.

Main complaint: attacked by two dogs, smashing him two thoracic vertebrae, causing later spastic paralysis, paralysis and bladder.

Points used: B23, and 36, BP6, B40, B60, VG 13, VG 16, VG 20, BP 34.

Results: partial improvement, with weekly applications. Used needles, electro-acupuncture and moxibustion. 
5) Canine Lion - DASCHOUND, male, 8 years.

Main complaint: paraparesis later due to disc herniation at T13-T14 and L1, after a fall. It presents numerous espondiloartroses.

Points used: B23, R 3, and 36, 40, BP6, and 25, VG 13, VG 16, VG 20, ashi points

Results: overall improvement, with fortnightly applications. Used needles and moxibustion

6) Canine Boni - Shit tzu. Male 12 years

Main complaint: presenting with gait incoordination.

Points used: Bai Hui, R2, R3, B23, E 36, BP6.

Results: did not return, awainting news.

Used needles and moxibustion.

7) Canine Cruzeta - DASCHOUND, male, 12 years.

Main complaint: animail presenting paraparesis later, with change and deviation from the column in the lumbosacral region.

Points used: R2, R3, B23, B40, B60, F2, VG 13, VG 16, VG 20, ashi points.

Results: overall improvement, with monthly applications. Used needles and moxibustion.

8) Canine Snoopy - Poodle, male, 6 years.

Main complaint: MAD limping in pain in the thoracic cervical region (likely disc hernia).

Used Points: IG4, IG11, VB 34, B40, E36.

Results: improvement of pain. He did not return to the other sessions

Used needles and moxibustion.

9) Canine Kyra- Bulldog frances, female, 7 months.

Main complaint: carrier hemivertebrae (stenosis between T5 to T8), and lumbar spine compression (hernia L7-

S1) then paresis paralysis later.

Points used: VG13, VG16, VG20, B40, B60, B23, R2, R3, R6. Ashi points.

Results: underwent two brain surgeries, improve almost complete, with weekly applications. Used needles and moxibustion.

10) Canine Adele French -Buldogue, female, 4 years.

Main complaint: paraparesis later in pain after an accident playing with other dogs. Great sensitivity lumbosacral region.

Used Points: Bai Hui, VG 13, VG 16, VG 20, B23, B40, B25, B59, VB34.

Results: $90 \%$ improvement, weekly applications. Used needles and moxibustion.

11) Feline Agre - SRD, male, 6 years.

Main complaint: Fell when climbing a tree, and presented pain and difficulty to walk after that. Its owners did not want to make an Rx.

Used Points: Bai Hui, VG 13, VG 16, VG 20, B23, VB 34.

Results: improvement report with an application. Scheduled just 2 fortnightly applications. Used needles and moxibustion.

The results obtained so far were:

\section{Results and Discussion}

1) Canine Abraham- partial improvement, requiring seminal application. Used needles and moxibustion.

2) Canine Cherie -.partial improvement, requiring seminal application. Used needles, electro-acupuncture and moxibustion.

3) Canine Boneca- overall improvement, with monthly maintenance applications. Used needles and moxibustion.

4) Feline Boneca-partial improvement, with weekly applications. Used needles, electro-acupuncture and moxibustion.

5) Canine Lion - overall improvement, with fortnightly applications. Used needles and moxibustion

6) Canine Boni - did not return, awainting news.

7) Canine Cruzeta - overall improvement, with monthly applications. Used needles and moxibustion.

8) Canine Snoopy - improvement of pain. He did not return to the other sessions

9) Canine Kyra- underwent two spine surgeries, improve almost complete, with weekly applications.

10) Canine Adele French -90\% improvement, weekly applications.

11) Feline Agre - improvement report with an application. Scheduled just 2 fortnightly applications.

It is necessary teaching Integrative Therapies and Complementary in undergraduate courses in the health area. In Veterinary Medicine, has substantially increased the search for acupuncture, for its antiinflammatory effect and analgesic already notorious success of that used in racehorses to alleviate muscle pain, joint damage and behavioral change. Similarly, a wide range of treatment options, acupuncture has been increasingly used in animals and company, according to the study Robinson [7], Schoen [15] and Mello [16]. 
Macciocia [4] is quite emphatic about the need for knowledge of the basic fundamentals of Traditional Chinese Medicine and Acupuncture to start treatment. This confirms the importance of mini-course and meetings that the teacher responsible is promoting with the students who support this project, as well as providing continuing education data for the same, to enable them to understand and define the treatment for each animal.

\section{Conclusion}

Students involved in the project are familiar with the basic terms and concepts of acupuncture, and taking the first steps in this science, following the case, watching the application technique of the needles, manipulation of moxibustion and electroacupuncture. They also give assistance to patients watching, marking new sessions and calling when those responsible are missing, trying to keep the continuity of care.

The intention is that this project of continuing and practical Study of Veterinary Acupuncture will become a Permanent Program in the Clinic School of the Faculty of Veterinary Medicine of UNIFESO.

\section{References}

[1]. B. A. Alteroche and P. Navailh,O Diagnóstico na Medicina Chinesas(São Paulo, SP: Andrei Editora, 1992).

[2]. M.V.O.Scognamillo-Szabó and G.H.Bechara,Acupuntura: Bases científicas e aplicações.Ciencia Rural, 31 (6), $2001,1091-1099$.

[3]. D. Draehmpaehl and A. Zohmann, Acupuntura no Cão e no Gato:princípios básicos e prática científica(São Paulo, SP: Editora Roca, 1997)

[4]. G. Macioccia,Diagnóstico na Medicina Chinesa:um guia geral(São Paulo, SP: Editora Roca, 2006).

[5]. M. Casasola, Acupuntura en Animales(Madrid. Espana: Mandala Ediciones, 1999).

[6]. A. M. Hayashi andJ.M. Matera,Princípios gerais e aplicações da acupuntura em pequenos animais: revisão de literatura, Revista de Educação Continuada em Medicina Veterinária e Zootecnia, 8(2), 2005, 109-122.

[7]. N.G. Robinson, Veterinary Acupuncture: an ancient tradition for modern times, Alternative \& Complementary Therapies,13(5), 2007, 258-265.

[8]. D. Stein, A Cura Natural para Cães e Gatos(São Paulo.SP: Editora Ground,1998).

[9]. T.S. Wen, Acupuntura Clássica Chinesa(São Paulo, SP: Editora Cultrix, 1985).

[10]. H. Xie, V. Preast,Xie's Veterinary Acupunture(Iwoa.EUA: Blackwell Publishing, 2013)

[11]. G. Macioccia,The Channels of Acupuncture.Clinical Use of the Secondary Channels and Eight Extraordinary Vessels.(London,UK :Churchill Livingstone,2006)

[12]. C. Schwartz, Quatro Patas Cinco Direções:um guia de medicina chinesa para cães e gatos (São Paulo.SP: Ícone Editora, 1996).

[13]. G.Macioccia, Os Fundamentos da Medicina Chinesa(São Paulo,SP: Editora Roca, 1996).

[14]. A.M. Hayashi andJ.M. Matera,Evaluation of electroacupuncture treatment for thoracolumbar intervertebral disk disease in dogs,Journal of American Veterinary Medical Association,231(6), 2007, 913-918.

[15]. A.M. Schoen,Acupuntura Veterinária:da arte antiga à medicina moderna, 2(São Paulo.SP: Editora Roca,2006).

[16]. M.L.V. Mello.Estudo Comparativo de alguns Aspectos da Aplicação da Acupuntura em Medicina Humana e Medicina Veterinária,specialist in Acupunture monog., Centro Brasileiro de Acupuntura, Niterói, RJ, 2009. 